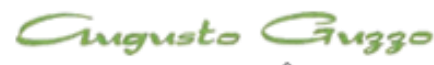

REVISTA ACADÉMICA

\title{
Ética periodística e identidad profesional
}

\author{
Juan Carlos Suárez Villegas ${ }^{1}$ \\ Recebido em: 01/03/2013. Aprovado em: 31/03/2013. Disponibilizado em: 24/06/2013
}

1. Juan Carlos Suárez Villegas, profesor Dr. de deontología periodística y filosofía política en la Universidad de Sevilla. Evaluador de la Agencia Nacional de Evaluación y Prospectiva (ANEP) y de la Agencia Italiana de Evaluación de Investigación y Universidades (ANVUR). Autor de una docena de monografías y una treintena de aportaciones en revista científicas y capítulos de libros en Comunicación y Filosofía Política. Entre sus últimas publicaciones, "Libertad de expresión e investigación periodística", en la revista Sistema, (enero, 2013). Es miembro de la Comisión Deontológica de la Federación de Asociaciones de la Prensa de España (FAPE).

* Artículo con la entusiasta recomendación de publicación. Dr. Víctor Silva Echeto. Universidad de Playa Ancha (Chile).Investigador Comisión Nacional de Investigación Científica y Tecnológica de Chile (CONICYT). http://vsilvaecheto.blogspot.com).

\section{Resumen}

La Deontología es una disciplina a caballo entre la Ética y el Derecho. Sus pautas no tienen las fuerzas normativas de las leyes, pero adquieren un importante peso como obligaciones profesionales, las cuales podrían ser refrendadas posteriormente por los tribunales de justicia como exigencias de la diligencia debida en el ejercicio de una determinada profesión. La deontología se puede convertir en un instrumento de análisis de la actividad informativa y ofrecer así un paradigma de la ética de la profesión periodística. La definición de una serie de principios básicos de la ética periodística, la delimitación de un procedimiento para llevar a cabo el análisis deontológico, o la distinción entre el análisis y la crítica son algunas de las ideas básicas en las que se basa la presente propuesta.

Palabras clave: ética, deontología, crítica, análisis, información, códigos.

\begin{abstract}
The ethics is a discipline somewhere between ethics and law. Their guidelines are not regulatory forces of the law but are important professional obligations, which could be subsequently endorsed by the courts as due diligence requirements of the exercise of a particular profession. Ethics become a tool for analysis of information. The definition of a set of basic principles of journalistic ethics, the definition of a procedure for carrying out the analysis of ethics, or the distinction between analysis and criticism are some of the basic ideas on which this proposal is based.
\end{abstract}

Keywords: ethics, criticism, analysis, information, codes. 


\section{Introducción}

Ut officie nihilig enihilis dolupta pel ium corro moloriae poris natem quam quis aut la cum exerund ipsant, autatque volupti sintiur aut optate plaut am landaeperum cus doluptiatur, consequ atint, et ratinus deleni non re, sim harum nos event ut est aut fugia natis experunt quiducia con nitio veniet asitem quunt dolorro eate perum voluptatium ent, que iusdaepudi conetur?

El presente artículo es resultado de un proyecto de investigación sobre la excelencia en el ámbito de la práctica periodística. Dicha investigación tuvo una parte de trabajo de campo, de la que ya hemos dado cuenta en otros trabajos, y una parte teórica cuyo objetivo era extraer de la disparidad de normas deontológicas incluidas en los códigos de la profesión una serie de principios rectores que permitiera engarzar dichas pautas de actuación con principios más generales del periodismo. Una vez analizados más de setenta códigos relacionados con la actividad informativa en España, procedentes tanto de la profesión, de instituciones o de asociaciones de la sociedad civil, pudimos advertir que esta diversidad de pautas podía ser recogida bajo unos principios éticos generales de la profesión periodística.

Estos principios vendrían a configurar lo que podríamos denominar la teoría tridimensional de la ética, de acuerdo con las tres direcciones en las que los profesionales han de interrogarse sobre su grado de responsabilidad.

En primer lugar, la responsabilidad hacía sí mismo, como persona que pretende mantener coherencia en sus actos, basada en principios y valores arraigados en la conciencia de lo justo y razonable en el trato con los demás.
En segundo lugar, la responsabilidad hacia el resto de compañeros de oficio, quienes para hacer viables los fines de la profesión y acreditar así su compromiso de servicio a la ciudadanía, asumen una serie de restricciones en sus libertades y se organizan para hacer efectivos sus derechos frente a presiones externas al periodismo (Sinova, 2003). En tercer lugar, su responsabilidad con la ciudadanía, tanto cuando es objeto de la actualidad informativa, respetando sus derechos, como cuando es el destinatario de la información.

A este respecto, el periodista ha de ofrecer una información veraz, obtenida de manera lícita y diligente, además de garantizar su independencia de cualquier interés espurio que pueda condicionar su calidad, así como atendiendo a las responsabilidades educativas y sociales de la comunicación (Alsius y Salgado, 2010).

\section{Principios éticos del periodismo}

Estas tres dimensiones de la ética periodística podrían concretarse en una serie de principios básicos. Se trataría obviamente de una distinción analítica por razones de claridad metodológica, pues en cualquier deliberación práctica estarán implicados cada uno de ellos aunque lo hagan con distinto énfasis.

El principio de honestidad exige coherencia entre las decisiones que se adoptan y valores éticos fundamentales de la dignidad de la persona, tales como el respeto a su igual consideración o a su autonomía. Un modo en el que se podría revisar la honestidad consistiría en observar si las acciones que realizamos se corresponden con ciertas máximas que aceptaríamos como principios de actuación también para nosotros, o si las aplicamos con la misma integridad para cualquier situación similar, 
sin mezclar intereses particulares con la prioridad del respeto a los demás.

Esta propuesta estaría en línea con la ética del deber kantiano, si bien nos parece que un universalismo rigorista $y$ formal podría conducir a mandatos tan imperativos como vacíos. Por eso, la honestidad cabría entenderla mejor en una reflexión sobre las propias intenciones, conocidas solo por el sujeto, y si éstas se fundamentan en fines éticos tanto generales, como el respeto a la dignidad de los demás, como específicos, en el caso del periodismo, buscando la verdad y contándola como un derecho fundamental de la ciudadanía. Este principio concierne a la dimensión de la ética que mira hacia dentro, que interroga al sujeto sobre sus prioridades para recordarle que no cualquier objetivo es adecuado, sino que éste debe estar incardinado en el respeto a los demás y al servicio que se presta a través de su labor profesional.

Ahora bien, las personas no somos "islas" en medio del mar, sino que formamos una sociedad y queremos que las instituciones que rigen la convivencia tengan también una dimensión ética. De hecho, aunque la ética concierne a la acción del propio sujeto, su instrucción en una conducta ética depende en gran medida de la calidad ética del ambiente o sociedad en la que vive, pues por un proceso de ósmosis psicológica tendemos a adoptar las mismas conductas que observamos en otros. Pues los principios éticos no se aprenden de manera teórica, labor que sólo corresponde a un ejercicio de reflexión de quien se dedica a su estudio, sino a través de los comportamientos que aprendemos y sobre los que después reflexionamos.

Esta es la razón por la que Aristóteles establecía ya que para ser "ético" lo que había que hacer es actuar correctamente, cuyo ejemplo encontramos en el hombre sabio. Pero no se trataba de hacer lo mismo que él, de una manera mecánica, sino actuar por los mismos motivos que él actuaba así. Es decir, a través de la acción se aprende a ser más competente y justo como persona, y cuando uno echa la mirada atrás comprende las razones por las que tiene sentido hacerlo así y no de otro modo. En cambio, costaría mucho más esfuerzo explicar el valor (la eficacia práctica) de cierto modo de actuar a quienes no lo hacen, pues la experiencia moral se entiende desde la coherencia entre las motivos y las acciones.

Por tanto, la ética es individual pero también social, y ambas cuestiones se reclamaban como extremos de una misma realidad que sería la conciencia moral. El sujeto piensa al mismo tiempo tanto desde un punto de vista social, es decir, en función de cómo las conductas vienen consideradas por la sociedad, como desde un punto de vista moral, más próximo a los sentimientos que experimentamos como personas frente a la realidad de los demás, condición que nos permite reflexionar y reaccionar frente a decisiones o convenciones sociales que puedan alejarse de los propósitos humanos para los que fueron concebidas. Así, por ejemplo, cabría establecer un punto de vista de "la justicia legal" y la justicia en su sentido más radical de los méritos o desméritos de una conducta desde el punto de vista moral. Por eso, cuando alguien queda absuelto por la ley puede mantener un sentido de culpa; y al revés, alguien condenado puede saber que lo es injustamente. También podría ocurrir con otros asuntos en los que se tolera cierta corrupción social y se condesciende con una mala praxis, pero que desde el punto de vista moral se advierte que esta conducta no se compadece con los valores que alumbra nuestros sentimientos morales como persona.

Quien actúa de manera ética desea que la propia sociedad comparta esos criterios éticos. Por eso, quien es honesto no aspira a presumir de esta cualidad como una virtud 
individual, sino que procura que sean cualidades que se prediquen de las propias instituciones que rigen la sociedad. Para lograr este objetivo, que convierte la ética desde un asunto individual en la conducta de un colectivo profesional, se requiere que todos asuman acuerdos y compromisos para limitar su libertad, así como adoptar medidas que fortalezcan sus derechos. De este modo se le pondría un techo social a la ética individual que quedaría protegida por el compromiso de la profesión, pues la ética no sería sólo una virtud individual sino también una "virtud pública", convirtiéndose la honestidad en compromiso en el ámbito de la actividad profesional.

Dicho compromiso requiere un respeto más específico a las decisiones que se adoptan entre todos para favorecer ciertos bienes comunes, incluyendo ciertos derechos de los periodistas que sólo serán tomados en serio si todos los defienden por igual y con la misma contundencia. Por tanto, cumplir con acuerdos adoptados por los profesionales constituye otro principio ético que podríamos denominar el principio de justicia, pues se trataría de defender libertades y deberes que sean iguales para todos, a fin de evitar ventajismos que terminen por imponer una lógica individual en la que cada cual rompa la ética profesional por distintos lados. A su vez, este principio de respeto a las normas profesionales, establecidas a través de la autorregulación, tendría que ubicarse como un círculo concéntrico de acuerdo que tendría que estar dentro del principio más amplio y general del respeto a la ley, es decir, de la legalidad como marco de actuación que rige para cualquier ciudadano. El periodista no tiene una patente de corso para saltarse las leyes, y su primer criterio de actuación es actuar dentro de ellas y, además, hacerlo por motivos éticos y no meramente jurídicos. Esta actitud no será óbice para que el periodista emplee toda su energía en criticar y denunciar los abusos que se puedan cometer en nombre de la ley, pues cumplir la ley no significa docilidad ante el poder sino responsabilidad como ciudadano.

Por otro lado, en situaciones excepcionales cabria admitir respuestas excepcionales que podrían contemplar una infracción como "método" (camino) para llegar a demostrar situaciones de injusticias ante las cuales la propia ley y sus agentes permanecen impasibles. Con mucha frecuencia, por estados de corrupción generalizada en los que los agentes de la ley actúan en connivencia con el propio delito. Se trata de desmontar que la apariencia de legalidad pueda servir de tapadera para encubrir tramas urdidas contra los intereses públicos.

En cualquier caso, el periodismo debe desenvolverse en condiciones normales cumpliendo con la ley y, especialmente, en aquellos supuestos que conciernen a los límites que tutelan los derechos de los ciudadanos, como el honor, la intimidad y la propia imagen. Además, ha de buscar la información por medios lícitos y con unos criterios de interés público y veracidad.

Por tanto, la justicia, entendida en su doble dimensión de establecedora de acuerdos que fortalecen la deontología profesional y vigilante del cumplimiento de la ley como marco dentro del cual se deben celebrar dichos acuerdos, constituye la base de la autorregulación o corregulación de la profesión periodística. De esta manera, el autocontrol de la profesión periodística transmite la fuerza de estos acuerdos a los fines de la actividad informativa, los cuales podrían ser recogidos bajo tres principios básicos, el primero de los cuales es el principio de diligencia, cuyo núcleo sería asegurar la veracidad informativa en todas sus fases, en la búsqueda de la información y en el momento de la transmisión. Este principio estaría destinado a controlar el 
modo en que se "manipula", en su sentido literal, los episodios de la realidad para convertirla en noticia como un producto que ha de reunir unas cualidades que satisfagan el derecho a la información de los ciudadanos.

A tal efecto, el periodista profesional, a diferencia de otros que participan de esta especie de transmisión automática de los hechos como si fuera un eco social, procurará elaborar la información con unos criterios de calidad que pasan por la contrastación de las fuentes, la pluralidad, su capacidad de contextualizar los acontecimientos, separar éstos de sus opiniones, descartar rumores $y$ especulaciones o mantener un equilibrio informativo en la presentación de las partes implicadas. Estas, entre otras medidas, conciernen al denominado principio de veracidad, entendida no como una verdad absoluta de los acontecimientos, sino como una actitud diligente destinada a asegurar que el público los conozca del modo más completo y pueda generar un debate público sobre los mismos.

Pero, además del "cómo" elaborar la noticia con diligencia, el periodista ha de atender también a ciertos objetivos de la actividad informativa en la sociedad democrática, tales como el pluralismo, la integración de las minorías, la protección de la infancia, la igualdad de la mujer, la tolerancia o la formación en temas de políticas para lograr una ciudadanía activa (Barnett, 2010). En otras palabras, cualquier labor comunicativa es al mismo tiempo una labor educativa, por lo que el periodista ha de pensar previamente sobre cómo determinados contenidos pueden afectar a estos propósitos del periodismo en una sociedad democrática. Una noticia puede ser diligente, pero si va dirigida a reiterar discursos xenófobos o machistas, adolecerá de su esencia democrática de lograr una ciudadanía más formada, libre e igualitaria, crítica pero a la vez respetuosa (Christians, 2010).

Ahora bien, para lograr tanto una información de calidad que asegure la verdad, como una información responsable, es preciso garantizar otro principio fundamental de la actividad informativa: la independencia. Dicho principio adquiere una doble dimensión. Por un lado, un deber para que el periodista no se venda y se convierta en vocero de intereses comerciales, políticos y empresariales que puedan filtrarse a través de su labor informativa sin advertir al público de estas intenciones. Otra forma más burda de incurrir en una infracción de este principio sería directamente dejarse sobornar activa o pasivamente a través de ciertas promesas, contraprestaciones $\mathrm{O}$ regalos, de los que el periodista se pueda considerar deudor, para contar la verdad o decir lo que piensa. Sin independencia no puede haber ni verdad informativa ni responsabilidad social del periodista.

Por otro lado, la independencia constituye una condición necesaria para ejercer el periodismo, por lo que se deben reconocer unos derechos de los profesionales para proteger la propia calidad de la información. Por eso, las organizaciones profesionales han de tener como función primordial fortalecer los derechos de los periodistas frente a las condiciones en las que llevan a cabo su trabajo dentro de las empresas informativas. Este deterioro de la independencia también puede venir por las draconianas condiciones laborales y unas retribuciones míseras que obliguen a los profesionales a ver en el periodismo más una actividad ocasional que una dedicación y compromiso con la ciudadanía (Figueras y otros, 2012).

Por tanto, la ética profesional es como una bicicleta que combina el movimiento de dos ejes que se coordinan y transmiten su fuerza para avanzar en una misma dirección. 
Estas dos ruedas serían el autocontrol, asumiendo acuerdos comunes para fortalecer sus deberes y derechos, y la responsabilidad social, como marco de objetivos hacia los que se debe conducir la actividad informativa. La correa que facilita el engranaje entre ambas ruedas sería la honestidad e independencia del profesional, como condición fundamental para evitar cualquier forma que adultere la esencia del periodismo.

Así, el periodista tiene una triple responsabilidad: hacia su propia conciencia, hacia los compañeros y hacia la ciudadanía. El derecho de los ciudadanos es el objetivo específico de la actividad y ha de fundamentar cualquier acuerdo de la profesión, al tiempo que define una prioridad en las intenciones del profesional para establecer prioridades. Es decir, como periodista, por las decisiones que he adoptado en mi vida, he asumido ciertas responsabilidades y no otras con los ciudadanos.

\section{Principios éticos y pautas generales de actuación}

A continuación, vamos a señalar algunas de las cuestiones deontológicas que caerían bajo cada uno de estos principios éticos:

\subsection{El principio de Veracidad}

\subsubsection{Sobre el interés público}

Se debe atender al interés público de los acontecimientos, a fin de justificar por qué determinados episodios de la realidad merecen un tratamiento informativo. Ha de conocerse a la ciudadanía para entender el interés del público, que corresponde al interés subjetivo de la audiencia, que se alimenta con nuevos episodios de curiosidad y morbo para convertirlo en divisa de intercambios en las conversaciones privadas.

\subsubsection{La calidad del proceso informativo. (Diligencia profesional)}

- Tipos de fuentes (fiabilidad, posible contaminación).

- Comprobación de los hechos por diversas fuentes.

- Respetar los hechos y distinguirlo de lo que puedan ser opiniones o especulaciones del periodista. Es preciso el rigor informativo, aunque el periodista pueda adoptar una determinada óptica social o política desde la que relate los acontecimientos.

- Ofrecer versiones plurales y representativas de los agentes implicados en las noticias.

- Titulares apropiados con los hechos y evitar el sensacionalismo como aditivo informativo.

- Uso adecuado de las imágenes en el que exista consonancia entre el relato de la noticia y la narración audiovisual, evitando que éstas sean apropiadas para producir ciertas asociaciones a través de la imagen.

- Rigor en la terminología tanto jurídica como de carácter técnico cuando se trata de noticias de periodismo especializado.

- Rectificaciones en los mismos términos que se ocasione un perjuicio intencionado o no a terceras personas.

- Derecho de réplica para que las partes afectadas por el tratamiento de una información pueda ofrecer sus versiones. 


\subsection{Cuestiones concernientes al principio de honestidad}

En Deontología se señala la honestidad como una cualidad de las opiniones, es decir, como un requerimiento para que más allá de la veracidad que deriva del relato de los hechos se puedan aportar criterios pertinentes para su interpretación. En este sentido, el periodista ha de actuar con el propósito de conducir a la opinión sobre los motivos y propósitos que justifican el devenir de unos acontecimientos que pueden parecer espontáneos y que, sin embargo, corresponden a intereses o movimientos de los que convienen advertir a la opinión pública.

No se puede confundir la opinión como profesional de la comunicación de la información privada. El periodista que utiliza la tribuna pública para abordar cuestiones que conciernen a asuntos personales, de los que forma parte y juez, se arriesga a convertir el artículo de opinión en instrumento de vejación hacia terceros afectados por esos mismos hechos. Por eso, un criterio recomendable sería que el columnista no opte por convertir las páginas del periódico en un escenario en el que dar rienda suelta a sus filias y fobias personales, dejando este tipo de contenido para otros formatos como cartas al director, o su blog personal.

1. Fomentar la opinión pública es una tarea de alta responsabilidad y debería guardar una serie de requisitos deontológicos con los que se pueda apreciar su honestidad.

2. Pertinencia: que esté fundada sobre los hechos relevantes de los acontecimientos sobre los que se construye la opinión.

3. Respeto: Es admisible la máxima crítica pero siempre acompañada del máximo respeto a la dignidad de colectivos o

Augusto Guzzo Revista Acadêmica, 2013, No 11, 11-25 personas sobre los que se vierte la opinión.

Responsabilidad social: por la autoridad social que se le presupone a quien ejercer una opinión pública parece lógico esperar que su discurso no incite a comportamientos inadecuados o que realice afirmaciones de mal gusto y poco sensible con la realidad social.

Además del ejercicio de la opinión podemos señalar otras cuestiones de la práctica profesional en la que también podría apreciar el grado de honestidad de los profesionales. Por ejemplo, en la relación entre el periodista $y$ la fuente de información, advirtiendo de su condición de periodista y de sus propósitos con las indagaciones para las que le requiere, a fin de que la persona conozca los posibles usos que se puedan hacer de sus declaraciones.

\subsection{Cuestiones concernientes al principio de justicia}

Se requiere cumplir con lo dispuesto en la ley en relación con la tutela de los derechos de las personas que pueden verse afectados en sus derechos por una mala praxis profesional. En el caso del periodismo se trataría de evitar prácticas que atenten contra el honor, la intimidad y la propia imagen de las personas de manera injustificada y motivada por el propósito de obtener una mayor rentabilidad económica, tratando las historias de las personas como si éstas fueran meras mercancías del espectáculo informativo.

Que dicho principio adquiera una dimensión deontológica supone que su cumplimiento no debe venir motivado por las sanciones legales, sino sobre todo por una voluntad ética y bien intencionada de respeto a las personas. Con este propósito, la deontología aspira a complementar al Derecho con pautas más específicas y 
adaptadas a las situaciones concretas. De ahí que en los códigos y otros documentos deontológicos encontremos de manera detallada criterios complementarios que deben presidir la actuación del profesional en relación con los derechos de las personas que protagonizan la información.

Dichos derechos deben ser respetados de manera más escrupulosa e intensa en los momentos de especial dolor y aflicción. En este apartado, la deontología puede constituir un complemento importante a los mínimos legales.

Otras prácticas que podrían quedar recogidas en este espíritu de la justicia entendida como respeto al "compañerismo" profesional, a la condición de igualdad con otros colegas, serían las siguientes:

- No recurrir a métodos ilícitos para la obtención de la información.

- No condicionar la verdad informativa por la influencia de grupos de poder o económicos, así como por intereses personales del periodista. Este principio afecta también a la verdad informativa, pues comporta un engaño para el público, pero además constituye una ventaja del profesional frente a sus compañeros y constituye uno de los mayores riesgos del periodismo en la actualidad: la información al servicio de intereses comerciales. Dada la relevancia de esta exigencia, trataremos sus distintos aspectos bajo el principio de independencia, el cual tendría sus raíces en este deber de defender la profesión frente al mercado.

- No plagiar informaciones de otros compañeros y citar debidamente la procedencia o autoría de informaciones tomadas de otras fuentes.
- Potenciar los derechos de los periodistas en las empresas informativas y en las organizaciones profesionales.

- Cumplimiento de los mismos deberes establecidos por la profesión para fortalecer bienes comunes, haciendo del código un punto de consenso para dirimir la buena praxis profesional. De este modo, el periodista acepta los cauces habilitados por la profesión para garantizar el cumplimiento del código profesional.

- Dentro de este principio, cabría introducir también el denominado principio de legalidad, referido al respeto que el profesional de la información ha de mantener hacia los derechos de las personas. El periodista ha de prestar mayor cuidado en evitar perjuicios gratuitos al honor de las personas, injerencias en su intimidad o una exposición que no haya sido consentida de su imagen.

\subsection{Cuestiones concernientes al principio de responsabilidad social}

Los medios de comunicación constituyen un referente de normatividad social. Es decir, de lo que dicen los medios se habla, se piensa y se actúa. Ellos dirigen el debate y consiguen que proyectemos nuestra atención a los temas de actualidad que nos presentan cada día. Por tanto, los medios de comunicación dotan de visibilidad a los temas, a las personas y a los colectivos sociales y, además, lo hacen otorgándoles una "identidad mediática" que se convierte con frecuencia en el horizonte del imaginario colectivo, es decir, de las creencias y prejuicios de la gente sobre las diversas cuestiones sociales.

Por esta razón, los medios adquieren una especial responsabilidad que ha de ser 
preservada con algunas pautas que garanticen un equilibrio comunicativo que presida la convivencia social. A este respecto, cabría recordar las siguientes como las más significativas:

- Se han de evitar estereotipos de identidades étnicas, religiosas, sociales, sexuales o nacionales que sean gratuitas $\mathrm{y}$ deriven en perjuicios sociales. $\mathrm{La}$ identidad no es una explicación de los hechos ni tiene por qué presumir una relación de causalidad con los mismos.

- Respeto del derecho a la igualdad de todas las personas, lo que incluye un tratamiento informativo respetuoso. Particular importancia adquieren en este sentido los comentarios sexistas contra las mujeres o expresiones culturales dirigidas a discriminarla de las mismas aspiraciones que los hombres. Esta misma atención se debe prestar con otros colectivos sociales especialmente vulnerables, tales como los inmigrantes, minorías religiosas, homosexuales, personas que padecen enfermedades mentales, etc.

- Protección de la infancia y la juventud evitando ofrecer datos que puedan conducir a su identificación en contextos conflictivos y que puedan condicionar su normal desarrollo psicológico y social.

- La información ha de ofrecerse de manera serena y con el sentido de la responsabilidad, a fin de evitar alarmas sociales que generen comportamientos irreflexivos y perjudiciales para los intereses de la ciudadanía.

- El tratamiento de temas de especial sensibilidad social, como los malos tratos contra las mujeres, los suicidios, comportamientos antisociales, etc., se ha de realizar con mesura y evitando el sensacionalismo, que puede ocasionar conductas miméticas.
- Los medios de comunicación son educadores permanentes de la opinión pública y han de cuidar no sólo los contenidos sino también las formas con las que estos vengan expuestos, por lo que han de rehuir expresiones de mal gusto, insultos, expresiones soeces $\mathrm{O}$ formas agresivas en el lenguaje.

- Respeto hacia las señas de identidad de cualquier colectivo social, étnico, religioso o de cualquier otra naturaleza. Se puede ejercer la máxima crítica con el máximo respeto. La ofensa, más que un ejercicio de libertad de expresión es una restricción a la igualdad de los colectivos más vulnerables para expresarse sin estar condicionados por los prejuicios $y$ estigmas de los discursos dominante de la mayoría. De lo contrario se podría incurrir en la denominada espiral del silencio.

\subsection{Cuestiones concernientes al principio de independencia}

La información, además de un derecho de los ciudadanos, es una importante arma de influencia social. Con ella se pretende orientar ideológicamente a los ciudadanos y también incentivarles en sus preferencias de consumo. Con esta finalidad, muchas empresas pretenden comprar el favor de los medios y periodistas para que les concedan un tratamiento informativo favorable a sus intereses comerciales. Este propósito se puede llevar a cabo de muchas maneras, pero desde luego existen algunas suficientemente explícitas como para que merezcan el reproche moral de la profesión. A este respecto hay que denunciar diversas formas de soborno que el periodista acepta, convirtiendo la información en una oportunidad para sus intereses personales. Dicho tratamiento, además de faltar a la honestidad que se le presupone a un periodista, constituye un claro fraude a la 
buena fe del público, que espera que la información no esté contaminada por intereses ajenos a los estrictamente informativos.

Por otro lado, el principio de independencia también hay que entenderlo de manera positiva, como una garantía de la ética del profesional frente a las presiones de la empresa para que ceda a favor de sus intereses.

La infracción de este principio se refleja porque se advierte un tratamiento más promocional que informativo, propiciando una imagen favorable de la marca y sin que exista una actitud crítica o distante sobre los pros y contras de los elementos de la noticia. También la deontología periodística establece la objeción ética de que el profesional que ha logrado un crédito social a través de su labor informativa lo ponga al servicio de intereses comerciales, evitando la realización simultánea de información y publicidad.

\section{Dimensiones prácticas de la deontología periodística. Análisis y crítica de la información.}

El periodismo no es una actividad mecánica consistente en elaborar noticias como productos de consumo. Se establecen dos dinámicas complementarias en el análisis ético de la noticia; una referida a las formas de hacer la noticia (deontología), y otra referida a los fines (valores) de la información, es decir, teleológica. En otras palabras, la noticia no sólo tiene que estar bien hecha, de acuerdo con los criterios de diligencia profesional, sino que ha de ser también una buena noticia, es decir, atender a los fines de la información en el marco de una sociedad democrática. Estas finalidades conciernen a las responsabilidades sociales de los medios de comunicación y aportan una dimensión creativa al periodismo, pues existen valores humanos cuya vigencia depende de la buena comunicación, tales como la propia calidad política de los ciudadanos, la formación de actitudes cívicas y tolerancia hacia la diversidad cultural. Por esta razón, desde esta perspectiva de las responsabilidades públicas cabría ponderar tanto lo que hacen los medios como aquello que "no hacen" y cuya dejación constituye un perjuicio para la ciudadanía.

En los códigos deontológicos la ética del profesional se concreta en deberes y serán éstos los que permitan llevar a cabo un análisis de la información (Jones, 1980). Estos deberes constituyen un protocolo de diligencia profesional para atender casos que surgen en la práctica diaria del periodismo. Estas pautas, por supuesto, deben ser interpretadas en cada contexto por el periodista para lograr satisfacer el propósito de informar y respetar los derechos de las partes de una manera equilibrada $y$ razonable. La deontología es flexible para lograr el objetivo de informar salvando ciertos escollos, pero no es subjetiva ni personal, sino que se trata de cumplir con las responsabilidades de la profesión de acuerdo con la naturaleza de cada caso (Jiménez, 2013).

\section{Criterios para un análisis deontológico de la información.}

El ciudadano puede recabar de los profesionales de la comunicación las razones que justifican su tratamiento informativo. Esta dinámica de interactividad entre medios y público ha aumentado de manera extraordinaria con los medios digitales, pero las audiencias persiguen a fin de cuenta demandar una información más completa que incluya las versiones de los propios protagonistas de las noticias (Diezhandino, 2009). Por eso debería ser una práctica habitual que los ciudadanos pudiésemos consultar a través de diversas vías a los 
medios por aquellas prácticas informativas que nos parezcan controvertidas y que puedan afectar tanto a los derechos de las personas afectadas como al posterior derecho de los ciudadanos a una información veraz, contrastada y respetuosa. No hemos de olvidar que en todo acto informativo hay un acto de educación cívica; no sólo se informa sobre la realidad, sino que se enseña a mirarla, y a tratar a los demás colectivos a través del modo de presentarlos a la opinión pública (Bauman, 2013).

Este propósito sería la razón de ser del conjunto de documentos deontológicos con el que se dota la profesión y los medios de comunicación para cumplir con sus responsabilidades frente a la ciudadanía. Vamos a continuación a señalar cuáles serían estos distintos criterios que el periodista debe mantener a la hora de fundar la calidad de su conducta profesional (Real y otros, 2007).

- El marco jurídico: qué dispone el Derecho sobre el asunto tratado. ¿Hay una norma jurídica? El derecho marca el mínimo exigible en relación con las obligaciones del periodista. No hemos de olvidar que la norma jurídica obliga a todos y, además, genera una obligación moral en tanto que su cumplimiento no debe corresponder a una mera exigencia legal sino también al propósito de que su autoridad constituya una pauta común de justicia para todo. Por supuesto, esta actitud de respeto a la ley no supone renunciar a la legítima crítica que cualquier ciudadano puede y debe ejercer ante lo que considera una mala aplicación de la ley o una mala ley, máxime cuando de dicha labor crítica dependerá que se ponga de relieve las deficiencias del sistema social y político. Por tanto, la primera exigencia en el ejercicio del periodismo es cumplir con la ley, pero también el primer deber del periodista es criticar a las leyes cuando éstas pudieran adolecer de eficacia para lograr los fines de justicia que la fundamentan.

Por tanto, la labor de la deontología es complementaria con respeto a la ley y no sustitutiva. El criterio deontológico permite aportar una respuesta más ajustadas y concreta a las circunstancias del caso, complementando así las exigencias de la norma jurídica. De este modo, la deontología logra que de manera más discrecional y razonable las normas sean interpretadas en cada situación a la luz de los fines de la profesión.

En resumen, el periodista debe tener un buen conocimiento del marco legislativo que regula el derecho a la información y actuar en consecuencia, renunciando a utilizar métodos ilícitos para obtener la noticia y con el debido respeto a los límites impuestos por los derechos de las personas.

- El marco deontológico: concierne a las pautas de las que los profesionales se dotan a sí mismos para atender a su compromiso de servir a la ciudadanía en su derecho a ser informada de manera veraz y plural sobre cuestiones de interés público. La deontología podría ser considerada como un mosaico de pautas de comportamiento que acreditan la especial responsabilidad de los profesionales frente a los administrados. El referente de la deontología periodística lo establecen los distintos documentos conformados por la profesión, por el propio medio o por instituciones relacionadas con ciertos temas de especial sensibilidad social y que exigen un respeto en el tratamiento informativo que se les presta (asociaciones de mujeres, inmigrantes, minorías religiosas, juventud, enfermedades mentales). Los 
documentos deontológicos son muy variados y tienen un carácter de recomendación para el profesional.

\section{- Doctrina jurídica y deontológica:} Incluye, en primer lugar, los criterios establecidos por las instancias jurídicas (jurisprudencia establecida por el Tribunal Constitucional). En segundo lugar, y salvando la desproporción normativa con la doctrina jurídica, cabría aludir a los criterios hermenéuticos extraídos de las resoluciones dictadas por las instancias profesionales. Además de estas dos fuentes de doctrinas, jurídica y deontológica, cabría también incluir aquella que se pueda formular a partir de estudios científicos e investigaciones académicas que adviertan sobre ciertas cuestiones relativas a la actividad profesional que puedan ser pertinentes para fundamentar un razonamiento en la deliberación de un determinado caso.

- El sentido común: debe ejercer una importante función para orientarnos sobre la conveniencia de ciertas actuaciones a la luz de las circunstancias presentes, pues la corrección de una conducta debe también ir acompañada de la elección y las formas adecuadas, a fin de evitar que ciertas decisiones puedan ocasionar perjuicios innecesarios. Por tanto, el periodista, manteniendo como prioridad el bienestar de las personas, deberá discernir de qué modo gestionar su labor informativa para evitar molestias a las personas afectadas que sean innecesarias y que tampoco aporten mayor valor a la noticia. Por eso, el sentido común debe ser un criterio subsidiario para deliberar y resolver sobre situaciones no siempre contempladas por la casuística legal o deontológica.
- La costumbre: se trata de conductas espontáneas adoptadas como criterios de actuación en situaciones no regladas y que generan una expectativa razonable con respecto a la conducta de terceros. Por eso, la costumbre también puede ser un criterio de actuación en ciertas situaciones, si bien es un criterio débil.

A la hora de resolver una cuestión en la que entren en juego las responsabilidades del profesional, un litigio si deriva en un procedimiento jurídico, y una controversia si da lugar a una queja en el ámbito deontológico, se realiza un juicio práctico en el que, partiendo de la premisa de lo establecido por la norma o la pauta deontológica, se delibera sobre la propiedad o no de la conducta en relación a lo establecido en ella. En el caso del Derecho da lugar a una sentencia por parte de un tribunal de justicia, mientras que en el caso deontológico da lugar a una resolución. La sentencia es una respuesta del ordenamiento a una conducta y tiene previsto todo un sistema de sanciones que garantiza su obligatoriedad. En el caso de la deontología, el propósito consiste en el reproche público de una conducta y sus efectos sancionadores sólo podrían derivarse del desmérito de dicha conducta y la respuesta que pueda dar a ella un público responsable.

\section{Conclusión}

La acción humana puede ser interpretada bajo la luz de diferentes esferas de normativas más o menos difusa. Para algunos sus acciones sólo se justifican por su propia voluntad, sin tener mayor consideración a los acuerdos que se establezcan por parte de sus compañeros, para otros, en cambio, la única pauta obligatoria sería la ley y si algo no está recogido en una ley sólo cabe que cada cual actúe según sus propios criterios. Por nuestra parte, entendemos que los marcos de 
responsabilidad ética son más amplios, pues pueden existir responsabilidades de carácter social o político o profesionales, es decir, un grado del sentido del deber hacia los demás por la función social que uno desempeña y que debería presidir la legitimidad de sus actos. En cambio, este espacio correspondiente a lo que podríamos denominar una ética cívica ha desaparecido y nos movemos en una sociedad que de manera pendular gira del carácter rígido de la norma jurídica, apoyada en las sanciones correspondiente, o la más absoluta discrecionalidad por parte del sujeto. Este vaciamiento del sentido de la responsabilidad como un espacio flexible en que la libertad debe atender a los fines legítimos de ciertas actividades profesionales o públicas constituye una de los factores de la crisis actual de una sociedad de sujetos nómadas que sólo se relacionan con las leyes, como si éstas fuesen medidas imperativas para exigir conductas de terceros de manera coactiva. Creemos que sin la ética profesional y marcos de responsabilidad deontológica y pública se pierde una enorme oportunidad para dotar de mayor contenido a la autonomía de una sociedad cívica y responsable.

El núcleo de cualquier ética se halla en la honestidad personal. Después podríamos establecer la esfera de la actividad profesional, basada en los compromisos públicos para cumplir con los fines de una actividad. El marco legal sería el que daría unidad a esas obligaciones generadas en las diferentes parcelas que quedarían conectadas por un sistema de norma para dar soluciones sociales a los conflictos que puedan surgir tanto en las relaciones privadas como en el cumplimiento de las normas públicas. Se conforma así un conjunto de esferas jalonadas en su carácter normativo que iría desde las exigencias autoimpuesto por el sujeto para ser honesto a los deberes profesionales o el carácter rígido de la norma jurídica. La deontología sería un puente entre el sentido de la ética profesional y la norma jurídica, estableciendo pautas que sin ser tan rígido como las normas jurídicas si establecen una obligatoriedad de carácter moral para quienes deciden dedicarse a un determinado ámbito profesional o a una responsabilidad pública. Cada una de estas disciplinas constituyen como diferentes tramos del razonamiento práctico, como un continuo que va desde las reflexiones abiertas y difusas de los deberes profesionales en relación con la ética más genera arraigada en la conciencia del sujeto, a la normatividad rígida, de todo o nada, que establece la norma jurídica. El profesional debería advertir ambos extremos como alternativas abiertas entre las que debe transitar para ver la coherencia tanto de sus consideraciones personales como la de la norma jurídica, pues la legitimidad de los valores como la justicia y la igualdad deben estar también garantizado con el cumplimiento de las normas jurídicas.

Los principios que aquí proponemos son ejes de la deontología periodística y sirve para examinar las diversas pautas que conciernen a su responsabilidad en las tres dimensiones que hemos señalados: hacia la propia conciencia, hacia los compañeros de profesión y hacia la sociedad. En relación con esta último se ha de incluir el respeto a la ley como principio fundamental, si bien dicha obediencia no puede anular la capacidad reflexiva y crítica de quien ha de cumplir con ella y, por tanto, ciertos escrúpulos éticos cuando ésta no se compadezca con sus fines legítimos.

El periodismo es una profesión social, $y$ como tal administra un bien humano práctico que no puede quedar expuesto de manera discrecional al criterio de quienes lo ejercen. Las profesiones son prácticas sociales institucionalizadas que cuentan con una tradición basada en el compromiso ético con la ciudadanía. En la actividad 
profesional cabe distinguir dos tipos de relaciones entre el profesional y el administrado: una relación horizontal como personas y en la que ambos se deben respeto a sus derechos (honestidad), y otra de carácter vertical, en la que el profesional administra un determinado bien a la otra persona (diligencia y responsabilidad). Para garantizar el ejercicio de este derecho, la profesión ha de actuar cohesionada y comprometida en su conjunto (justicia), y priorizando los fines de la profesión por encima de cualquier otro de los que pueda recibir presión (independencia).

Podríamos decir que, así como no habría derecho a la educación sin maestros, ni derecho a la justicia sin juristas que lo hagan valer delante de los tribunales, tampoco habría derecho a la información en su sentido auténtico sin periodistas, personas que tengan la vocación de conocer, interpretar y contar lo que está pasando en la sociedad y cómo afecta a los derechos de las personas (Kovach y Rosentiel, 2003). Por eso, sin periodistas no hay periodismo y sin periodismo no hay democracia, pues el derecho a la información, como ocurre con los otros derechos básicos, no se puede hacer depender de la actividad espontánea y de la curiosidad humana para interesarse por este $u$ otro asunto, sino que se precisa de instituciones profesionales que garanticen que ese derecho es administrado con una determinada cualidad para conocer los hechos de interés público de manera veraz y promover así el ejercicio de una razón pública dialogante (Ward y Wasserman, 2010).

\section{Bibliografía}

1. Alsius, Salvador; Salgado, Francesc (eds.) (2010): La ética informativa vista por los ciudadanos. Contraste de opiniones entre los periodistas y el público, UOC, Barcelona.

2. Barnett, S. (2010): "El pluralismo de los medios en la era digital. Periodismo, democracia e interés público". Infoamérica. Iberoamerican Communication Review, núm. 3-4. págs. 41-56. Cátedra Unesco de Comunicación. Universidad de Málaga, España.

3. Bauman, Zygmunt (2013): Sobre la educación en un mundo líquido. Conversaciones con Ricardo Mazzeo, Paidós, Barcelona.

4. Christians, Christians (2010). "The Ethics of Universal Being”, en Ward, Stephen J. A. Wasserman, Herman. Media Ethics Beyond Borders: a global perspective. New York/London: Routledge

5. Diezhandino, María (2009). Criterio Noticioso: el quehacer periodístico ante el desafío digital. Pearson Educación, Madrid.

6. Figueras Maz, M., Mauri Ríos, M., Alsius Lavera, S. y Salgado de Dios, F., (2012): “La precariedad te hace dócil. Problemas que afectan a la profesión periodística". El profesional de la información, Vol. 21, núm.1, págs. 70-75, enero-febrero.

7. Jiménez Gómez, Eva (2013), Retos de la enseñanza de la ética de la comunicación. Reflexiones a partir de una experiencia docente (2012-2013), en Juan Carlos Suárez Villegas (eds), Libro de Actas del II Congreso 
Internacional de Ética de la Comunicación.

Dykinson, Madrid. pp. 216-226

8. Jones, Clement (1980): Mass Media Codes

of Ethics and Councils. A Comparative International Study on Professional Standards, UNESCO, París.

9. Kovach Bill, Rosentiel Tom (2003). Los elementos del periodismo. El País, Madrid.

10. Puppis, Manuel (2009): Organizations of media self-regulation. European Press councils in comparison, Herbert von Halem, Colonia.

11. Real Rodríguez, Elena; Agudiez Calvo,
Pinar y Príncipe Hermoso, Sergio (2007): "Periodismo ciudadano versus Periodismo profesional: ¿somos todos periodistas?”, Estudios sobre el Mensaje Periodístico, Vol. 13, (189-212).

12. Sinova, Justino (2003): “Acerca de la responsabilidad pública del periodista. La verdad, los derechos de los públicos y otras exigencias éticas del trabajo informativo", Doxa Comunicación, $\mathrm{N}^{\mathrm{0}}$ 1, pp. 171-184.

13. Ward, S. J. A. Wasserman, H. (2010). Media Ethics Beyond Borders: a global perspective. New York/London: Routledge. 